\title{
Accuracy and precision of four common peripheral temperature measurement methods in intensive care patients
}

This article was published in the following Dove Press journal:

Medical Devices: Evidence and Research

I September 2016

Number of times this article has been viewed

\author{
Simin Asadian' \\ Alireza Khatony' \\ Gholamreza Moradi² \\ Alireza Abdi' \\ Mansour Rezaei ${ }^{3}$ \\ 'Nursing and Midwifery School, \\ Kermanshah University of \\ Medical Sciences, ${ }^{2}$ Department of \\ Anesthesiology, ${ }^{3}$ Biostatistics \& \\ Epidemiology Department, \\ Kermanshah University of Medical \\ Sciences, Kermanshah, Iran
}

\begin{abstract}
Introduction: An accurate determination of body temperature in critically ill patients is a fundamental requirement for initiating the proper process of diagnosis, and also therapeutic actions; therefore, the aim of the study was to assess the accuracy and precision of four noninvasive peripheral methods of temperature measurement compared to the central nasopharyngeal measurement.
\end{abstract}

Methods: In this observational prospective study, 237 patients were recruited from the intensive care unit of Imam Ali Hospital of Kermanshah. The patients' body temperatures were measured by four peripheral methods; oral, axillary, tympanic, and forehead along with a standard central nasopharyngeal measurement. After data collection, the results were analyzed by paired $t$-test, kappa coefficient, receiver operating characteristic curve, and using Statistical Package for the Social Sciences, version 19, software.

Results: There was a significant meaningful correlation between all the peripheral methods when compared with the central measurement $(P<0.001)$. Kappa coefficients showed good agreement between the temperatures of right and left tympanic membranes and the standard central nasopharyngeal measurement ( $88 \%)$. Paired $t$-test demonstrated an acceptable precision with forehead $(P=0.132)$, left $(P=0.18)$ and right $(P=0.318)$ tympanic membranes, oral $(P=1.00)$, and axillary $(P=1.00)$ methods. Sensitivity and specificity of both the left and right tympanic membranes were more than for other methods.

Conclusion: The tympanic and forehead methods had the highest and lowest accuracy for measuring body temperature, respectively. It is recommended to use the tympanic method (right and left) for assessing a patient's body temperature in the intensive care units because of high accuracy and acceptable precision.

Keywords: body temperature, thermometers, intensive care units, sensitivity and specificity, tympanic membrane

\section{Introduction}

Measuring body temperature is one of the oldest methods to discern a problem in both medical and nonmedical fields; ${ }^{1}$ in fact, proper functioning of the body is dependent upon keeping the body temperature within the normal range $\left(37.2^{\circ} \mathrm{C}-37.8^{\circ} \mathrm{C}\right)$, because an increase $\left(>41.5^{\circ} \mathrm{C}\right)$ or decrease $\left(>30^{\circ} \mathrm{C}\right)$ in body temperature can lead to death. ${ }^{2,3}$ Accurate determination of body temperature in critically ill patients is a fundamental requirement for initiating the proper process of diagnosis, and also therapeutic actions. For this purpose, measuring temperature with mercury, tape, digital, and tympanic thermometers are currently the commonly used methods. ${ }^{4}$
Correspondence: Alireza Khatony Nursing and Midwifery School, Kermanshah University of Medical Sciences, Ashayer St., Isar Sq., Kermanshah 67।46, Iran Email Akhatony@gmail.com 
Each method has many advantages and some disadvantages, so selecting the proper thermometer and a more rigorous method is crucial. ${ }^{1}$ For measuring body temperature, eight locations have been considered, which include the nasopharynx, esophagus, pulmonary artery, rectum, axillae, tympanic membranes, legs, and bladder. Ideally, it is better, if possible, that measurement of temperature be done by a thermometer that is noninvasive, hygienic, convenient, and affordable, and also the measured temperature value would be close to the core body temperature eventually. In fact, the gold standard method for measuring the core body temperature is by way of the pulmonary artery approach, ${ }^{5}$ but this method has some restrictions such as being invasive and applicable only under special circumstances, in critical care wards and for unconscious patients. ${ }^{1,6}$ Another accurate method, which is accepted as the standard approach, is the nasopharyngeal method, which is noninvasive and in which the temperature is measured by inserting a sensitive probe into the external opening of the nose and directing it to the pharynx, between the nose and ears..$^{5,7-9}$

Nowadays, the most common sites for measuring body temperature by local sensors include: oral cavity, tympanic membranes, pulmonary artery, axillae, rectum, esophagus, and gastrointestinal tract. Mouth, forehead, ears, and axillae are the most accessible parts of the body that have mostly been used by specialists in internal medicine to measure temperature; these sites show body temperature faster and easier, and in a noninvasive way, but the most appropriate method of measurement is still controversial. ${ }^{4,10}$

Several studies have been conducted for determining the most correct and accurate ways of measuring body temperature. In this regard, some authors have recommended the use of tympanic thermometers while others have not. ${ }^{1}$ Dzarr et al indicated that tympanic temperature is equal to core body temperature. ${ }^{11}$ However, Rubia-Rubia et al introduced axillary temperature measurement method as the best method and rejected the forehead approach. ${ }^{1}$ In this respect, Edelu et al recommended not using the axillary method. ${ }^{12}$ The results of Mazerolle et al's study showed that the oral method could not reflect the core temperature of the body correctly, ${ }^{10}$ while Chue et al and Barnett et al announced that temperature measurement by tympanic and oral methods can correctly show the core body temperature. ${ }^{13,14}$

\section{Aims and objectives}

Considering the importance of an accurate method for assessing the body temperature of patients in the intensive care unit (ICU) by using a thermometer, and the controversial findings of the previous studies, this study was conducted for determining the accuracy and precision of the four methods of temperature measurement (oral, axillary, tympanic, and forehead) when compared to the standard nasopharyngeal method.

\section{Methods}

In an observational prospective study in 2011, the accuracy and precision of the four methods for measuring body temperature have been investigated. The study population included all hospitalized patients of the Imam Ali Hospital in Kermanshah, west of Iran. Imam Ali Hospital is a center where open heart surgeries are accomplished. This study was approved by ethics committee of research deputy of Kermanshah University of Medical Sciences. The setting of the study was the ICU where patients are admitted after surgery; there were 11 active beds in the ICU. The samples were recruited according to the convenience method. The sample size was calculated based on the sensitivity and specificity of previous studies ${ }^{4-6,8}$, using statistical formula, with $95 \%$ confidence interval and accuracy of 0.05 . With regards to the sensitivity and specificity of previous studies that were between $64 \%-90 \%$, so, we considered the maximum sample size of 237 patients which included 163 without fever and 74 with fever.

Inclusion criteria for sampling were: patients being conscious; having spontaneous breathing; at least 24 hours out from surgery; stable hemodynamic status; absence of dysrhythmia; lack of medications affecting blood vessels; not taking nonsteroidal anti-inflammatory drugs; not using corticosteroids; having no anti-fever medications since 4 hours ago; absence of infection in ears and mouth; no ear trauma or wax and no tympanic membrane perforation; not having any wound, trauma, or dressing at the temperature measurement sites; and absence of anatomical abnormalities in ears and mouth. The research instruments included data collection sheets and four types of thermometers (tympanic, forehead, mercury [for oral and axillary], and nasopharyngeal). As the nasopharyngeal method had been used in various studies, it was considered to be the standard method. ${ }^{1,2}$ Furthermore, the results of these methods were similar to the other standard methods such as the pulmonary artery method. ${ }^{3}$ All the thermometers had been calibrated by the researcher before use for ensuring reliability. Repeated measurement of temperature at different time intervals, before and during data collection, was applied. The data collection sheet included questions about age, sex, blood pressure, duration of hospitalization, ambient temperature, and patient's body temperature at the five different locations. 
It is noteworthy that we considered the cut-off point as $38^{\circ} \mathrm{C}$, which was determined based on the Jahanpour et al's study. ${ }^{4}$

For data collection, the written informed consent was taken from the patients, then the researcher referred to the Imam Ali hospital and visited the patients. In this study, all temperature measurements were performed by one researcher for reducing possible biases, and core body temperature was measured by an anesthesiologist, using a nasopharyngeal thermometer. For each patient, a special thermometer was used, and oral, axillary, tympanic, and forehead temperatures were measured simultaneously, then nasopharyngeal temperature was measured immediately afterwards. In general, on average, each patient's temperature measurement process lasted 8 minutes.

For measuring the axillary temperature, the mercury thermometer (Jiangsu Company, Nanjing, People's Republic of China) was used. The mercury thermometer, after shaking and lowering the mercury below $35^{\circ} \mathrm{C}$ mark, was placed in the axillary cavity and the patient's body temperature was read after 5 minutes, and again at intervals of 2 minutes; the measurement was repeated again by placing the thermometer at the previous location and the values were recorded.

The oral temperature was measured by a mercury thermometer (Jiangsu Company). After shaking the thermometer and lowering the mercury below the $35^{\circ} \mathrm{C}$ mark, it was placed for 5 minutes at the posterior part of the tongue then the numbers were monitored and recorded. This process was repeated after an interval of 2 minutes at the previous location and the values were recorded.

Measuring the tympanic temperature was done by a tympanic thermometer (Jinus Company, AZ, USA). For this purpose, the researcher first pulled the patient's auricle back and up for direct visualization of the ear canal, then the tip of the probe was inserted into the ear canal after covering it with disposable plastic, like an otoscope, and pushed forward slightly for preventing air effects on the screen. The number shown on the digital screen as ear temperature was recorded. The temperatures of both the right and left tympanic membranes were measured separately; each two times, within 2 minutes, and values were recorded. For each measurement, the probe of the tympanic thermometer was replaced.

Forehead temperature was measured using a strip thermometer, model BC200 (Taiwantrade company, Taipei, Taiwan), made in Taiwan. First, the researcher cleaned the forehead with a soft cotton swab dipped in alcohol, and after skin was dry, the strips were placed on the forehead, above the eyebrows. After 30 seconds, when the color bar was fixed, the displayed number was recorded as the temperature of the forehead. Two minutes later, the process was repeated again.

Nasopharyngeal standard temperature was measured using a sensor attached to a monitor (Space Labs Medical America Company, Issaquah, USA) and a disposable probe. For this purpose, a probe thermometer was inserted through the external hole of the nose to $5 \mathrm{~cm}$ posterior of the pharynx (between nose and ears) by the anesthesiologist, and after a reading was fixed on the screen, it was recorded. The probe was replaced for each patient.

The environment temperature of the patients' rooms was measured on all days and it was between $27^{\circ} \mathrm{C}$ and $27.2^{\circ} \mathrm{C}$. In this study, the cut-off point of fever was considered as $\geq 38^{\circ} \mathrm{C}$ by nasopharyngeal temperature measurement.

For sampling, the researcher referred to the intensive care ward of the Imam Ali Hospital, after obtaining permission from the Vice Chancellor of Research and Technology affiliated to Kermanshah University of Medical Sciences, and coordinating with the officials from the hospital. Data were collected after obtaining written informed consent from the participants and necessary explanation about the purpose of the study and assurance related to the confidentiality and anonymity of information were given to them.

Data collection sheets were completed by the researcher. The data were compiled by the Statistical Package for the Social Sciences, version 19, software (IBM Corporation, Armonk, NY, USA) and analyzed by descriptive and inferential statistics. ${ }^{15}$ The paired $t$-test was used for assessing the precision; determining the accuracy; measuring the sensitivity, specificity, positive predictive value (PPV), negative predictive value (NPV), and also kappa coefficient tests were done. The sensitivity is the results of division "number of true positive" / "number of true positive" + "number of false negatives", and the specificity also calculated based on the division of "number of true negative" / "number of true negatives" + "number of false positives". PPV specified the possibility of being a patient (having fever in this study) and NPV indicated the likelihood of being healthy (without fever in this study). ${ }^{16}$ The sensitivity and PPV were applied for determining the rate of real positive patients (with fever), and specificity and NPV were done for determining the extent of real negative patients (without fever). Kappa coefficient was placed at five levels, from poor $(<0.20)$ to very good (between 0.81 and 1.00). For estimating the correlation between the different methods of temperature measurement and the standard method, the Spearman's 
correlation coefficient was used. In this study, significance level for all tests was $<0.05$.

\section{Results}

In this study, 237 patients were evaluated, most of them being males $(57 \%, \mathrm{n}=135)$. Mean and standard deviation of age was $63 \pm 11.89$ years. There was no fever in $68.7 \%$ of patients (163) and $31.2 \%$ of patients (74) had fever. In 219 cases (92.4\%), the environment temperature was $27^{\circ} \mathrm{C}$.

When comparing the precision of various methods of measuring body temperature, oral, axillary, right and left tympanic, and forehead, no significant difference was found between the first and second measurements by paired $t$-test $(\mathrm{P}>0.05)$ (Table 1). So it was concluded that they had sufficient precision for body temperature measurement.

For accuracy, the findings revealed a good correlation between the various methods of measuring body temperature and the standard method (Table 2).

As has been shown in Table 3, the right and left tympanic methods have more power for diagnosing the true positives patients (with fever) compared to other methods. The results of sensitivity and specificity tests, and PPV and NPV for determining the accuracy of the measurements showed that the right tympanic method with sensitivity $83 \%$, specificity $100 \%$, PPV 100\%, and NPV 93\% and the left tympanic

Table I The comparison of mean body temperature in repeated measurements of the five peripheral methods of right tympanic, left tympanic, oral, axillary, and forehead

\begin{tabular}{llll}
\hline $\begin{array}{l}\text { Temperature } \\
\text { measurement } \\
\text { methods }\end{array}$ & \multicolumn{2}{l}{ Statistical indices } \\
\cline { 2 - 4 } & $\boldsymbol{t}$ & $\mathbf{d f}$ & P-value \\
\hline Right tympanic & 1.00 & 236 & 0.318 \\
Left tympanic & 1.34 & 236 & 0.180 \\
Oral & 0.00 & 236 & 1.00 \\
Axillary & 0.37 & 236 & 0.706 \\
Forehead & 1.15 & 236 & 0.132 \\
\hline
\end{tabular}

Abbreviation: $d f$, degrees of freedom.

Table 2 Correlation between the different peripheral methods of body temperature measurements and the central nasopharyngeal method

\begin{tabular}{lll}
\hline $\begin{array}{l}\text { Temperature } \\
\text { measurement } \\
\text { methods }\end{array}$ & \begin{tabular}{l} 
Nasopharyngeal method \\
\cline { 2 - 3 }
\end{tabular} & $\begin{array}{l}\text { Correlation } \\
\text { coefficient }(\boldsymbol{r})\end{array}$ \\
\hline Right tympanic & 0.938 & P-value \\
Left tympanic & 0.932 & $<0.001$ \\
Oral & 0.829 & $<0.001$ \\
Axillary (armpit) & 0.776 & $<0.001$ \\
Forehead & 0.891 & $<0.001$ \\
\hline
\end{tabular}

Table 3 Diagnosing the patient with fever or without fever by the determined methods

\begin{tabular}{|c|c|c|c|}
\hline \multirow[t]{2}{*}{ Methods } & \multicolumn{2}{|c|}{ Standard } & \multirow[t]{2}{*}{ Total } \\
\hline & $\begin{array}{l}\text { With } \\
\text { fever }\end{array}$ & $\begin{array}{l}\text { Without } \\
\text { fever }\end{array}$ & \\
\hline \multicolumn{4}{|l|}{ Right tympanic } \\
\hline With fever & 62 & 0 & 62 \\
\hline Without fever & 12 & 163 & 175 \\
\hline \multicolumn{4}{|l|}{ Left tympanic } \\
\hline With fever & 60 & 0 & 60 \\
\hline Without fever & 14 & 163 & 177 \\
\hline \multicolumn{4}{|l|}{ Oral } \\
\hline With fever & 48 & 0 & 48 \\
\hline Without fever & 26 & 163 & 189 \\
\hline \multicolumn{4}{|l|}{ Axillary } \\
\hline With fever & 39 & 0 & 39 \\
\hline Without fever & 35 & 163 & 198 \\
\hline \multicolumn{4}{|l|}{ Forehead } \\
\hline With fever & 40 & 3 & 43 \\
\hline Without fever & 34 & 160 & 194 \\
\hline Total & 74 & 163 & 237 \\
\hline
\end{tabular}

method with sensitivity $83 \%$, specificity $100 \%$, PPV $100 \%$, and NPV 93\% had higher values (Table 4).

Comparison of agreement between different methods of measuring body temperature and the standard method were performed by the kappa test. The left and right tympanic methods had the highest (very good agreement) and forehead method had the least agreement with the standard method; there was significant agreement between all the procedures with the standard method, and also the accuracy of all methods was acceptable (Table 5). Figures 1-5 are five graphs of the Bland-Altman plot.

The receiver operating characteristic (ROC) curve was used for showing the highest and lowest accuracy of various methods of temperature measurement. In an ROC curve, the true positive rate (sensitivity) is plotted as a function of the false positive rate ( 1 - specificity) for different cut-off points of a parameter. The area under the ROC curve is a measure of how well a parameter can distinguish between two diagnostic groups (diseased/normal). The results indicated that the right tympanic and forehead methods had the highest and lowest accuracy, respectively (Figure 6).

\section{Discussion}

The aim of this study was to determine the accuracy and precision of four methods of measuring body temperature, which include oral, axillary, the left and right tympanic, and forehead, which were compared to the standard nasopharyngeal method. 
Table 4 Accuracy and precision indexes of temperature measurement methods compared to the standard nasopharyngeal method

\begin{tabular}{|c|c|c|c|c|c|c|}
\hline \multirow{2}{*}{$\begin{array}{l}\text { Temperature } \\
\text { measurement } \\
\text { methods }\end{array}$} & \multicolumn{6}{|l|}{ Indices } \\
\hline & Sensitivity & Specificity & $\begin{array}{l}\text { Positive } \\
\text { predictive } \\
\text { value }\end{array}$ & $\begin{array}{l}\text { Negative } \\
\text { predictive } \\
\text { value }\end{array}$ & $\begin{array}{l}\text { Paired } \\
\text { t-test }\end{array}$ & $\begin{array}{l}\text { Kappa } \\
\text { coefficient }\end{array}$ \\
\hline Right tympanic & 83 & 100 & 100 & 93 & 1.00 & 88 \\
\hline Left tympanic & 81 & 100 & 100 & 93 & 1.34 & 85 \\
\hline Oral & 64 & 100 & 100 & 86 & 0.00 & 72 \\
\hline Axillary & 52 & 100 & 100 & 82 & 0.37 & 60 \\
\hline Forehead & 54 & 98 & 93 & 93 & 1.15 & 59 \\
\hline
\end{tabular}

Table 5 The degree of agreement between different methods of temperature measuring with standard methods

\begin{tabular}{lll}
\hline $\begin{array}{l}\text { Methods for measuring } \\
\text { temperature }\end{array}$ & Kappa (\%) & P-value \\
\hline Right tympanic & 0.88 & $<0.001$ \\
Left tympanic & 0.85 & $<0.001$ \\
Oral & 0.72 & $<0.001$ \\
Axillary (armpit) & 0.60 & $<0.001$ \\
Forehead & 0.59 & $<0.001$ \\
\hline
\end{tabular}

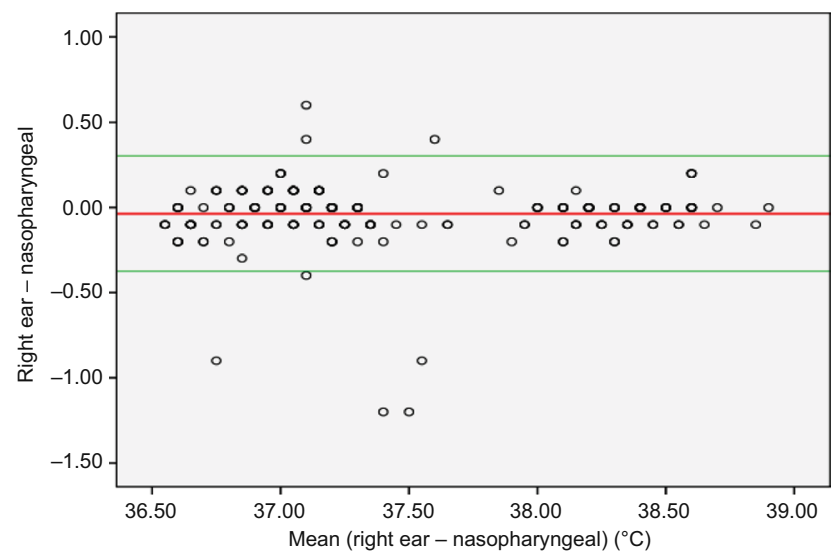

Figure I The Bland-Altman plot of right tympanic method of measuring temperature.

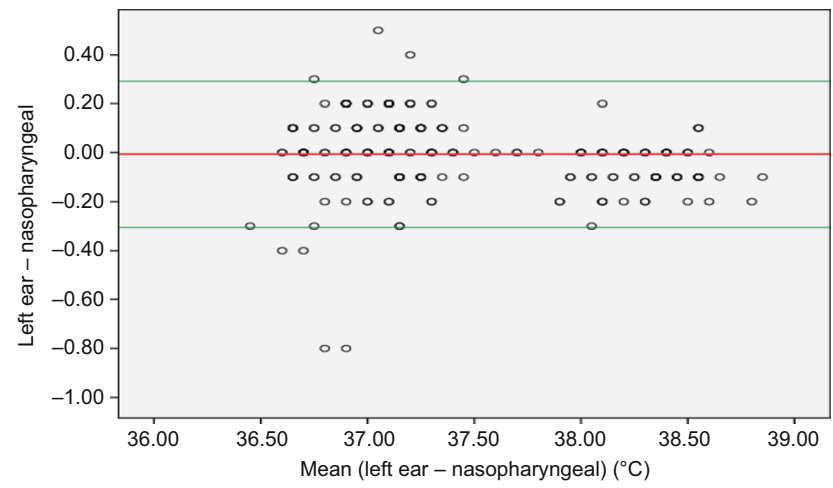

Figure 2 The Bland-Altman plot of left tympanic method of measuring temperature.

In this study, the right and left tympanic methods showed high precision, sensitivity and specificity (accuracy) in measuring the body temperature and high correlation with the standard method, as well as very good agreement of

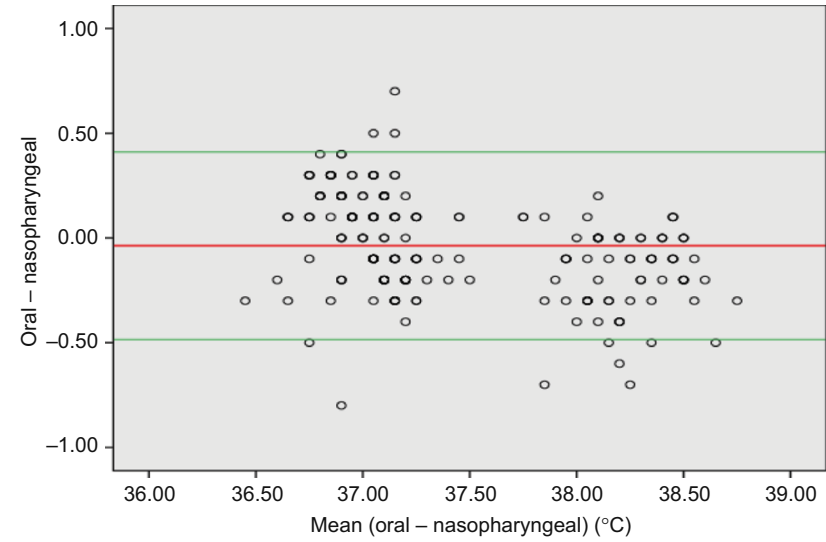

Figure 3 The Bland-Altman plot of oral method of measuring temperature.

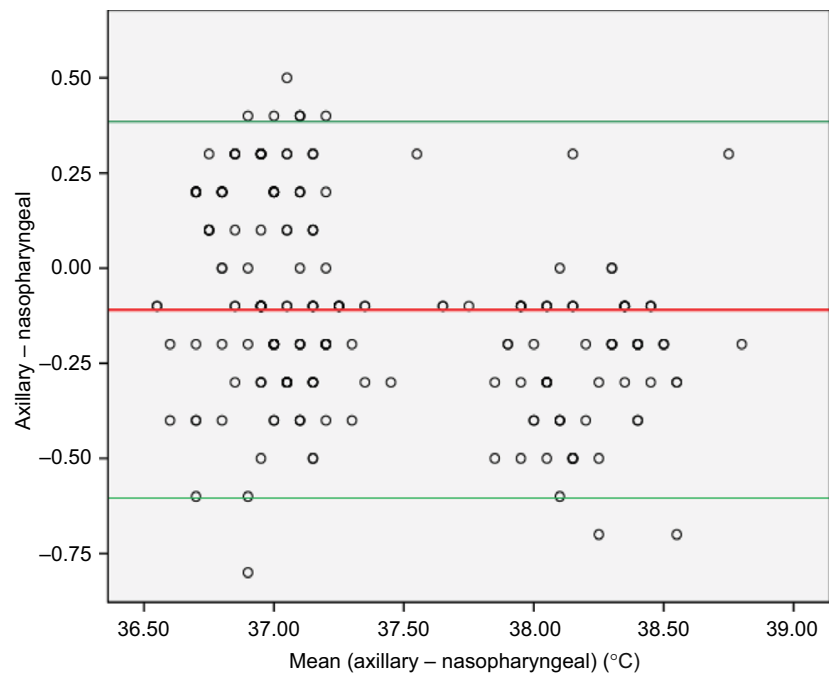

Figure 4 The Bland-Altman plot of axillary method of measuring temperature.

$88 \%$ for right tympanic and $85 \%$ for the left. The results of research by Dzarr et al, León et al, and Jahanpour et al are in line with our study, and have confirmed the high accuracy, precision, and sensitivity of tympanic method, ${ }^{4,11,17}$ while results of Barnett et al and Shamshiri et al are not consistent with our study. ${ }^{6,13}$ Lawson et al also stated that the tympanic method had lower accuracy and precision than the standard method. ${ }^{18}$ The authors believe that owing to the high degree of accuracy and precision, good correlation and agreement 
with the standard method, and also easy to use, accessibility, and ability to prevent transmission of infection, the right and left tympanic methods are the best procedures for measuring body temperature in the ICUs.

In this study, the oral method had an acceptable precision in measuring body temperature but good accuracy was not seen when comparing the oral and standard methods, considering agreement of $72 \%$ and low sensitivity and specificity. The results of studies by Dzarr et al, Rubia-Rubia et al, and Mazerolle et al also showed that the oral method was not good for measuring body temperature because of

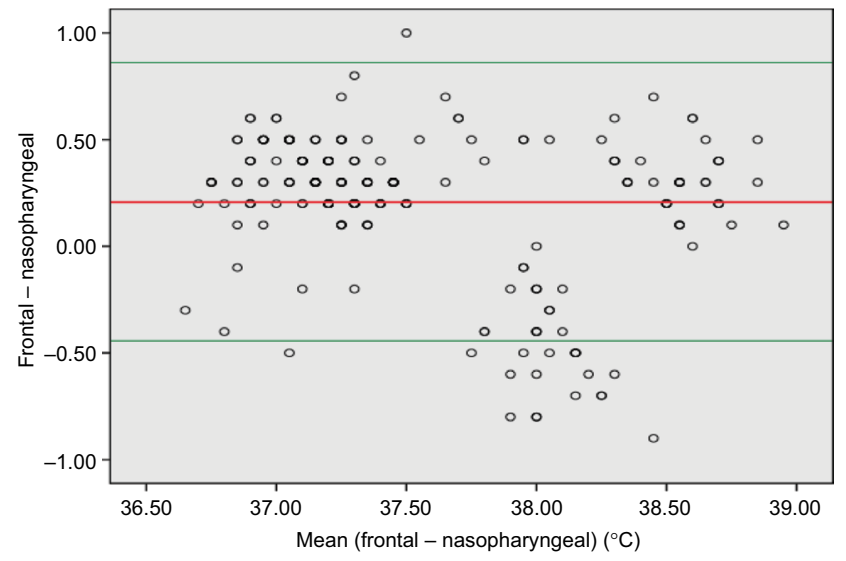

Figure 5 The Bland-Altman plot of frontal method of measuring temperature. lower sensitivity and specificity compared to the standard approach, which is consistent with our findings. ${ }^{1,10,11}$ But in Lawson et al's research, the oral method has shown good accuracy and high precision for indicating body temperature compared to the standard method. ${ }^{18}$ The oral method can be affected by internal and environmental factors such as hot and cold drinks and diseases of the oral cavity; thus it is not representative of core body temperature. ${ }^{18}$ Regarding our results, despite a high correlation with the standard method, the oral method has low sensitivity and also low PPV and agreement; therefore, it is not recommended for patients in ICUs.

Axillary temperature measurement had acceptable precision and good correlation with the standard method, but there was low sensitivity and specificity, and only $60 \%$ agreement. In this regard, Jahanpour et al's study also stated lower accuracy and agreement of the axillary method compared to the standard method, and is not recommended by them because of the low sensitivity and specificity; ${ }^{4}$ these findings are in line with our results. In studies by Rubia-Rubia et al and Khosravi et al, due to the high coefficient of Cronbach's, sensitivity and specificity; axillary method had good accuracy and precision. So the axillary method was suggested for measuring body temperature. ${ }^{1,19}$ Although the axillary method is a common, simple, and accessible method, with

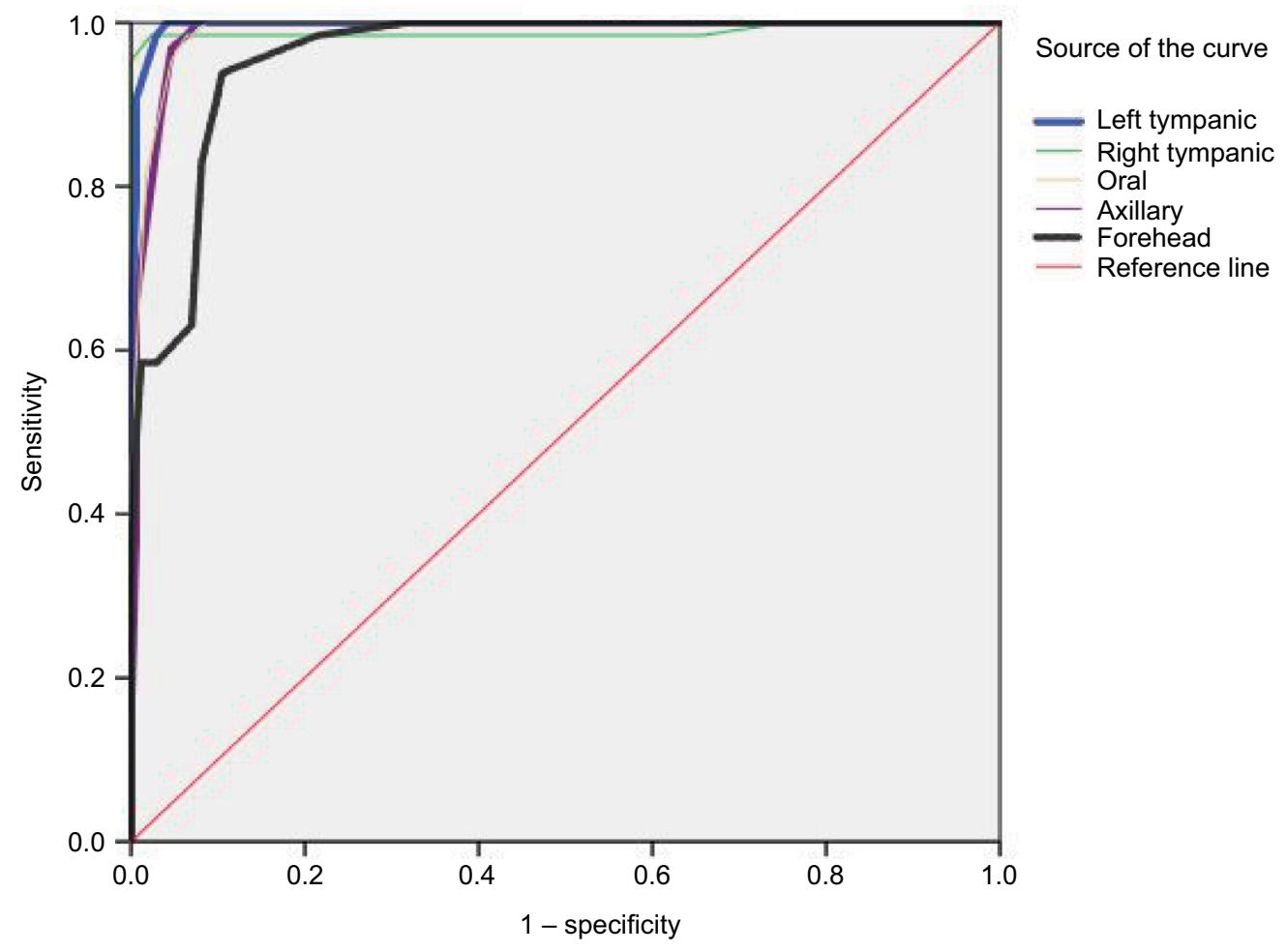

Figure 6 Sensitivity and specificity of different methods of temperature measurement using the ROC curve.

Abbreviation: ROC, receiver operating characteristic. 
respect to the agreement of only $60 \%$ and lower sensitivity and specificity then the standard method, it is not a good alternative for measuring core body temperature.

In our study, for determining body temperature, the forehead method had high precision, low sensitivity and specificity, and moderate agreement (59\%) with the nasopharyngeal method. This is in in accordance with the research by Ganio et al and Rubia-Rubia et al, which also stated low sensitivity, specificity, and agreement with the standard method. ${ }^{1,20}$ But Lawson et al's study indicated that the frontal method was a good method considering the high accuracy, precision, and agreement compared to the standard method, and advised use of this method for assessing body temperature. ${ }^{18}$ Although the frontal method had acceptable precision and high correlation with the standard method, it is cannot be used in intensive care wards because of the very low agreement coefficient, sensitivity, and specificity.

\section{Limitations}

Limitations of the study were ambient temperature and environmental conditions, which were controlled by providing similar conditions for all patients, as well as continues checking of room temperature during 24 hours and stability of patients hemodynamic. All measurements were carried out by one researcher, which might have led to some biases such as "self-fulfilling prophecy bias". For performing measurement by forehead thermometer and preventing the infection transmission, the researcher used a soft cotton swab dipped in alcohol to clean the patients' forehead; the skin was allowed to dry completely before checking the temperature, and this could have changed the measured body temperature.

\section{Recommendation}

It is recommended to perform similar studies in other hospital units, and if possible, pulmonary artery and bladder catheter methods would also be used as a standard for temperature measurement.

\section{Conclusion}

The results showed that all the methods have enough precision for measuring body temperature. With regard to accuracy, tympanic and forehead approaches showed the highest and lowest accuracy compared to the standard method, respectively. Therefore, it is recommended that, owing to the high accuracy, acceptable precision and advantages, such as being noninvasive, quick, easy to use, and availability, the tympanic method (left and right) be considered a good procedure for measuring body temperature of patients in ICUs.

\section{Acknowledgments}

The researchers express their appreciation and thanks to the officials of research department of Kermanshah University of Medical Sciences, Imam Ali Hospital, nursing staff and the participating patients, for assisting in carrying out of this research. This manuscript is taken from the MSc thesis of the first author which was approved by the research department of Kermanshah University of Medical Sciences.

\section{Disclosure}

The authors report no conflicts of interest in this work.

\section{References}

1. Rubia-Rubia J, Arias A, Sierra A, Guirre-Jaime A. Measurement of body temperature in adult patients: comparative study of accuracy, reliability and validity of different devices. Int J Nurs Stud. 2011;48(7):872-880.

2. Moran DS, Mendal L. Core temperature measurement. Sports Med. 2002;32(14):879-885.

3. Singh M, Pai M, Kalantri SP. Accuracy of perception and touch for detecting fever in adults: a hospital-based study from a rural, tertiary hospital in Central India. Trop Med Int Health. 2003;8(5): 408-414.

4. Jahanpour F, Azodi P, Zare N. A comparative study on temperature accuracy between tympanic, rectal, and axillary sites. Iran J Med Sci. 2015; 33(1):49-53.

5. Akata T, Setoguchi H, Shirozu K, Yoshino J. Reliability of temperatures measured at standard monitoring sites as an index of brain temperature during deep hypothermic cardiopulmonary bypass conducted for thoracic aortic reconstruction. J Thorac Cardiovasc Surg. 2007;133(6):1559-1565.

6. Shamshiri MAHM, Masroor D, Hajikazemi ES, Haghani H. Accuracy and precision of tympanic temperature in the reflection of core temperature. Iran J Nurs. 2006;19(47):57-65.

7. Kaukuntla H, Harrington D, Bilkoo I, Clutton-BrockT, Jones T, Bonser RS Temperature monitoring during cardiopulmonary bypass - do we undercool or overheat the brain? Eur J Cardiothorac Surg. 2004;26(3): 580-585.

8. Stavem K, Saxholm H, Smith-Erichsen N. Accuracy of infrared ear thermometry in adult patients. Intensive Care Med. 1997;23(1):100-105.

9. Wass CT, Long TR, Deschamps C. Entrapment of a nasopharyngeal temperature probe: an unusual complication during an apparently uneventful elective revision laparoscopic Nissen fundoplication. Dis Esophagus. 2010;23(1):33-35.

10. Mazerolle SM, Ganio MS, Casa DJ, Vingren J, Klau J. Is oral temperature an accurate measurement of deep body temperature? A systematic review. J Athl Train. 2011;46(5):566-573.

11. Dzarr AA, Kamal M, Baba AA. A comparison between infrared tympanic thermometry, oral and axilla with rectal thermometry in neutropenic adults. Eur J Oncol Nurs. 2009;13(4):250-254.

12. Edelu BO, Ojinnaka NC, Ikefuna AN. A comparison of axillary with rectal thermometry in under 5 children. Niger Med J. 2011;52(4):207-210.

13. Barnett BJ, Nunberg S, Tai J, et al. Oral and tympanic membrane temperatures are inaccurate to identify Fever in emergency department adults. West J Emerg Med. 2011;12(4):505-511.

14. Chue AL, Moore RL, Cavey A, Ashley EA, Stepniewska K, Nosten F, McGready R. Comparability of tympanic and oral mercury thermometers at high ambient temperatures. BMC Res Notes. 2012;5:356.

15. Zhang $Z$. Univariate description and bivariate statistical inference: the first step delving into data. Ann Transl Med. 2016;4(5):91.

16. Collier J, Huebscher R. Sensitivity, specificity, positive and negative predictive values: diagnosing purple mange. J Am Acad Nurse Pract. 2010;22(4):205-209. 
17. León C, Rodríguez A, Fernández A, Flores L. Infrared ear thermometry in the critically ill patient: an alternative to axillary thermometry. $J$ Crit Care. 2005;20(1):106-110

18. Lawson L, Bridges EJ, Ballou I, Eraker R, Greco S, Shively J, Sochulak V. Accuracy and precision of noninvasive temperature measurement in adult intensive care patients. Am J Crit Care. 2007;16(5): $485-496$.
19. Khosravi A, Sohrabi MB, Haratipoor H, Zolfaghari P. Accuracy and precision of body temperature measurement with infrared tympanic and axiliary thermometers compared with standard oral mercury thermometer. KAUMS Journal (FEYZ). 2006;9(4):43-49.

20. Ganio MS, Brown CM, Casa DJ, et al. Validity and reliability of devices that assess body temperature during indoor exercise in the heat. J Athl Train. 2009;44(2):124-135.

\section{Publish your work in this journal}

Medical Devices: Evidence and Research is an international, peerreviewed, open access journal that focuses on the evidence, technology, research, and expert opinion supporting the use and application of medical devices in the diagnosis, monitoring, treatment and management of clinical conditions and physiological processes. The identification of novel devices and optimal use of existing devices which will lead to improved clinical outcomes and more effective patient management and safety is a key feature. The manuscript management system is completely online and includes a quick and fair peer-review system. Visit http://www. dovepress.com/testimonials.php to read real quotes from authors.

Submit your manuscript here: https://www.dovepress.com/medical-devices-evidence-and-research-journal 